\title{
As Oficinas na Saúde Mental: Relato de uma Experiência na Internação
}

Mental health workshops:

Report of an experience in hospital admission
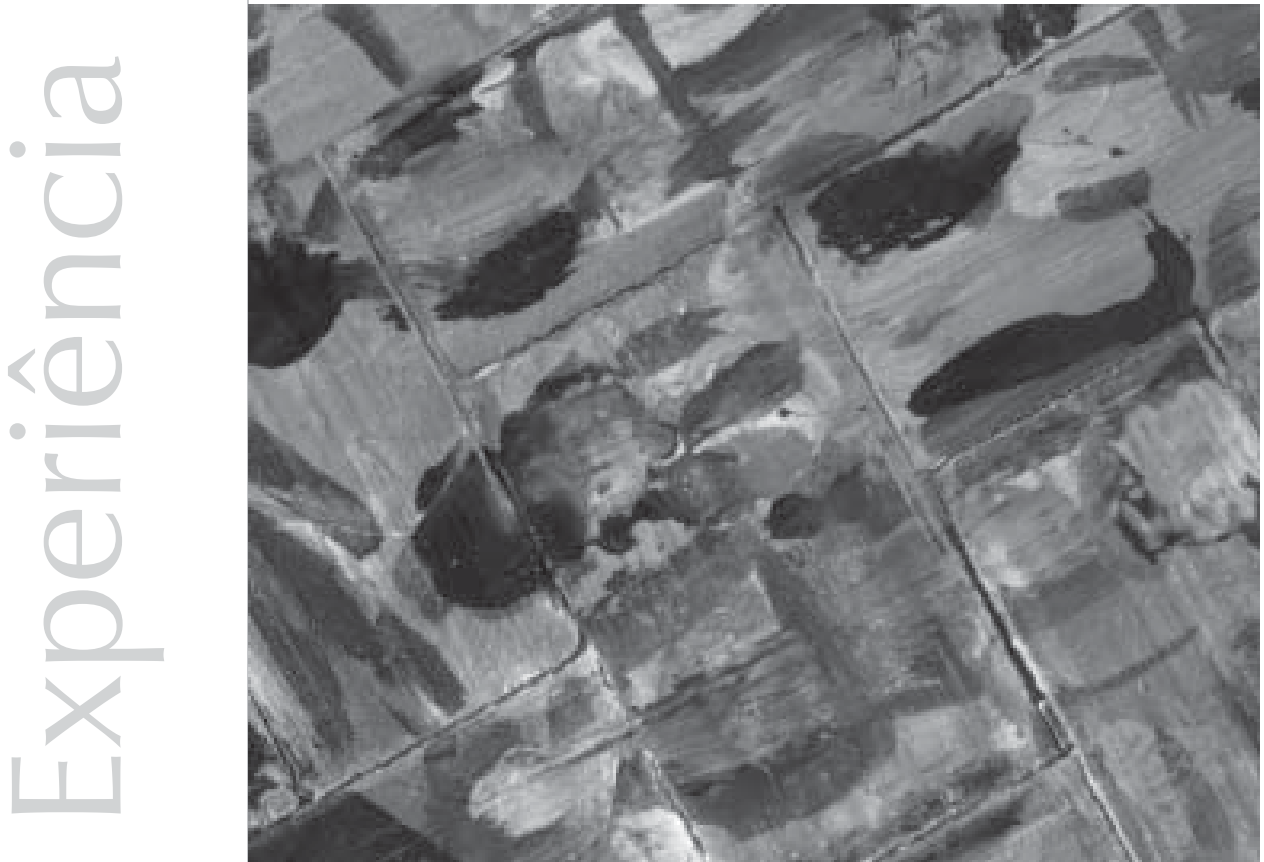
Resumo: O presente artigo trata da atividade das oficinas na internação psiquiátrica. Parte de uma breve explanação sobre a reforma psiquiátrica e discute a mudança no lugar social do psicótico, de excluído a cidadão. As oficinas terapêuticas, como parte das novas modalidades de atendimento no tratamento desses sujeitos, têm a função psicossocial aliada à clínica. Sua proposta é a expressão da singularidade e subjetividade dos sujeitos psicóticos, num espaço de convivência, criação e reinvenção do cotidiano na enfermaria psiquiátrica. O posicionamento do coordenador de oficinas será também aqui abordado, considerando-se as características da psicose e as peculiaridades no seu manejo. Serão relatadas as experiências das oficinas de letras e de salão de beleza, realizadas no Hospital Raul Soares, de Belo Horizonte.

Palavras-chave: saúde mental, enfermaria psiquiátrica, oficina terapêutica.

Abstract: This present article deals with the workshop activities at the psychiatric entering. It starts with a brief explanation about psychiatric reform and tells about the changing of the psychotic in the social place, from a socially excluded person into a citizen. The therapeutic workshops along with the new modalities of attendance in the treatment of these citizens have both psychosocial and clinical roles. Their purpose is the expression of the singularity and subjectivity of the psychotic citizens, in a place of creation and reinvention of the daily routine at the psychiatric infirmary. This article will also deal with the positioning of the workshops coordinator, taking into consideration the characteristics of psychosis and the peculiarities in its handling. The experiences in the text and beauty parlor workshops, held at the Raul Soares Hospital, in Belo Horizonte, will be described.

Key words: mental health, psychiatric infirmary, therapeutic workshop.

A reforma psiquiátrica, que completa vinte anos, propôs a desconstrução e a desinstitucionalização das práticas hospitalares, paralelamente à formulação de novos modelos de assistência ao portador de transtorno mental. O modelo asilar dos hospitais psiquiátricos veio sendo gradualmente substituído pelo tratamento em sistema aberto ou extra-hospitalar. Os NAPS1, CAPS ${ }^{2}$, CERSAMs ${ }^{3}$, centros de convivência e hospitais-dia testemunham esse processo.

Pretende-se, então, desmontar a lógica da exclusão, da contenção e do enclausuramento à qual o hospital psiquiátrico era jungido com a introdução de novas modalidades de intervenção no tratamento do paciente psicótico.

O discurso da cidadania entende o paciente psicótico como um cidadão capaz de interagir com a sociedade e de circular em seus espaços, nos quais a comunidade também circula. Pode-se mencionar, a título de ilustração, a apresentação do espetáculo do
Grupo Galpão, do FIT (Festival Internacional de Teatro, que acontece de 2 em 2 anos em Belo Horizonte), no HRS (Hospital Raul Soares). Tal discurso possibilita dissociar do imaginário social a idéia de que a loucura está ligada a periculosidade, a deficiência, a deterioração, ao isolamento e ao sentido de incapacidade e imprevisibilidade.

As ações de promoção da cidadania para os pacientes portadores de transtornos psíquicos demonstram como a clínica e a política se articulam. Tais programas representam uma possibilidade de resgate da cidadania dos portadores de transtorno mental.

\section{Breve reconstituiçâo histórica}

Primeiramente, por um discurso moral, o paciente psicótico foi alijado da sociedade junto a outros excluídos, contraventores, leprosos, ladrões, prostitutas. Internava-se sem vocação médica, simplesmente para excluir os
1NAPS - Núcleo de Assistência Psicossocial 2CAPS - Centro de Atenção Psicossocial

3 CERSAMS - Centros de Referência em saúde Mental 
desviados e desregrados. Posteriormente, com o advento da psiquiatria, a loucura é tomada como doença, apropriada pelo discurso e instituição médicos; esse paciente é então, isolado em manicômios.

Introduziram-se atividades com fins terapêuticos na instituição psiquiátrica. Estas foram, inicialmente, ligadas ao trabalho (colônias agrárias, laborterapia, ergoterapia e outras) e serviam ao propósito de disciplinar e reabilitar o doente mental e adequá-lo à ordem vigente dos manicômios.

No pós-guerra, com a ascensão dos direitos humanos, começou-se a pensar o doente mental como cidadão, sujeito de direitos e deveres, num processo de desconstrução/ reconstrução da lógica assistencial e dos fundamentos teóricos acerca da loucura.

"Nos novos dispositivos da rede de atenção, a ênfase na particularidade de cada caso, o trabalho multiprofissional, a escuta e o respeito ao louco e a invenção de novas estratégias de intervenção sobre o campo social e clínico deram ensejo à recuperação do uso da atividade como um valioso recurso no tratamento clínico e na reabilitação psicossocial"

Guerra
No Brasil, na década de 40, Nise da Silveira, psiquiatra de formação junguiana e herdeira da experiência bem-sucedida da terapia ocupacional, introduz, no Rio de Janeiro, a arte-terapia. Para tanto, aplica técnicas elaboradas de fortalecimento e expressão do eu, concebidas a partir da descoberta psicanalítica do inconsciente, em oficinas de expressão como pintura, escultura, música, dança e trabalhos manuais, e em atividades recreativas - jogos, passeios, festas.

Hoje, as oficinas constituem-se em novas práticas, propostas de inserção social nos hospitais psiquiátricos, num espaço de convivência, criação e reinvenção do cotidiano nessas instituições, pois, além do tratamento clínico indispensável, o sujeito psicótico necessita ter reconstituído seu direito de criar, opinar, escolher, relacionar-se.

Mesmo tendo a reforma psiquiátrica proposto o fim dos manicômios, sabe-se que, para as crises agudas dos pacientes psiquiátricos, entretanto, a internação faz-se necessária. São os serviços substitutivos de emergência que recebem o cidadão em seu momento de crise, surto psicótico, tentativa de auto-extermínio, homicídio, etc., quando este precisa da contenção para tratamento urgente e intervenção adequada. Temos, porém, de considerar ainda, na internação, os pacientes que permanecem por longos períodos nas instituições psiquiátricas por não terem condições sociais, afetivas e/ou financeiras de manter-se na sociedade. Para esses, um novo projeto de tratamento vem sendo proposto. Trata-se da passagem gradual de uma tutela completa para uma tutela parcial ou uma autonomia assistida, nos novos programas de assistência.

\section{As oficinas}

As oficinas procuram caminhar no sentido de permitir ao sujeito estabelecer laços de cuidado consigo mesmo, de trabalho e de afetividade com os outros, determinando a finalidade político-social associada à clínica.

"Nos novos dispositivos da rede de atenção, a ênfase na particularidade de cada caso, o trabalho multiprofissional, a escuta e o respeito ao louco e a invenção de novas estratégias de intervenção sobre o campo social e clínico deram ensejo à recuperação do uso da atividade como um valioso recurso no tratamento clínico e na reabilitação psicossocial" (Guerra, 2004, p.24).

A atividade artística enfatiza o processo construtivo e a criação do novo através da produção de acontecimentos, experiências, ações, objetos; "reinventa" o homem e o mundo. Sob essa perspectiva, as atividades das oficinas em saúde mental passam a ser vistas como instrumento de enriquecimento dos sujeitos, de valorização da expressão, de descoberta e ampliação de possibilidades individuais e de acesso aos bens culturais.

A loucura traz a marca de uma diferença quanto à forma de organização subjetiva que permitiria ao paciente psicótico fazer um laço 
simbólico com a ordem social. Mesmo inserido na cultura, na linguagem e no cotidiano, o psicótico não está inserido na norma simbólica que permite a equivalência e a inscrição num registro sexual que estabelece o circuito de troca social.

Na concepção de Guerra (2004), o que diferencia e particulariza a atividade das oficinas na saúde mental das demais intervenções, coletivas ou não, é o fato de o paciente psicótico trabalhar com o objeto concreto, o que a autora define por "materialidade do produto."

"A oficina vincula-se mais estreitamente à questão do estatuto do objeto do que ao da própria fala, posto que o seu funcionamento, seja qual for a tendência da oficina (trabalho, arte, convivência, subjetividade), sempre referencia um produto, uma produção material" (Guerra,2004, p.40).

As oficinas produzem efeitos subjetivos e socializantes por operarem sobre uma superfície material concreta, que permite uma circunscrição do gozo fora do corpo do sujeito. As oficinas estariam, portanto, segundo Guerra, num campo inédito, numa interseção entre o lugar da clínica especificamente, de um lado, e o lugar das atividades coletivas, de cunho eminentemente sociopolítico, de outro. As oficinas estariam, de fato, no campo do tratamento possível da psicose, da clínica ampliada, que une política e clínica.

Em conivência com os ideais de ressocialização, mais que o desenvolvimento de habilidades, as oficinas prestam-se a introduzir, na cultura, a diferença que a loucura representa, convidando o portador de transtornos mentais a

"inserir-se em alguma forma de liame social, ou seja, participar de um conjunto de signos que o inscrevam enquanto ser social e político à medida que lhe for possível"

(Guerra, 2004, p.38).

\section{A internação}

Nossas oficinas realizam-se no interior do Hospital Raul Soares, no Centro Cultural Arthur Bispo do Rosário e na enfermaria feminina (salão de beleza). Os pacientes internos são diariamente convidados a participar das oficinas e sua adesão é espontânea.

O mundo do internado é o espaço institucional, em que o paciente mora, dorme, se alimenta, vive seus prazeres, afazeres, criações, relações..., onde, enfim, todos os aspectos de sua vida se desenvolvem sob uma única autoridade. A internação modifica brutalmente a vida do paciente, já que o controle de suas necessidades humanas passa a ser feito pela organização burocrática institucional. A tutela hospitalar, muitas vezes, demove o paciente de cuidar do próprio corpo e de seus objetos, e leva-o a perder a referência de privacidade e de seu direito a ela.

"O internado, ao chegar à instituição, traz consigo uma concepção de si mesmo que se tornou possível por algumas disposições sociais estáveis no seu mundo doméstico.

Ao entrar, é imediatamente despido do apoio dado por tais disposições. Começa a passar por algumas mudanças radicais em sua carreira moral, uma carreira composta pelas progressivas mudanças que ocorrem nas crenças que tem a seu respeito e a respeito dos outros que são significativos para ele" (Goffman, 1974, p.24).

O internado passa, então, por um "desculturamento", tendo seus hábitos particulares de vida transformados, o que dá início a uma série de rebaixamentos, degradações, humilhações e profanações do eu. O seu eu é mortificado sistematicamente, embora muitas vezes não intencionalmente. As oficinas oferecem, como espaço que possibilita a expressão criativa individual na coletividade da instituição psiquiátrica, uma
"A oficina vinculase mais estreitamente à questão do estatuto do objeto do que ao da própria fala, posto que o seu funcionamento, seja qual for a tendência da oficina (trabalho, arte, convivência, subjetividade), sempre referencia um produto, uma produção material"

Guerra 
alternativa de modificação do cotidiano e algum enodamento possível desse eu, onde o sujeito psicótico cria soluções que enlaçam real e simbólico na produção de um objeto imaginário.

"È na densidade de um objeto criado que a possibilidade de construção e circunscrição de um certo excedente libidinal se dá. A tarefa dos oficineiros é retornar esse excedente, esse mais de gozo, enquanto trabalho do próprio psicótico" (Guerra, 2004, p.55).

A vida nos manicômios é organizada a partir de uma funcionalidade em que até mesmo a ocupação física dos espaços é regida por uma lei que busca banir o imprevisto e o acidente a fim de manter a ordem.

A ênfase no espaço relacional e na reinvenção do cotidiano do hospital, no poder de decisão sobre suas atividadese no uso do direito de ir e vir fundamenta a nova prática de reabilitação do paciente psiquiátrico na instituição.
Todos os aspectos da vida desenvolvem-se no mesmo lugar, em contato com grande número de pessoas, e são regulados por regras explícitas e formais; não há possibilidade de existência do próprio, do particular, do singular. O imprevisto e o incidente são banidos ou abafados, no hospital, através da contenção dos técnicos e da instituição, através de uma burocracia autoritária e de regras coercitivas. "As instituições hospitalares têm um ritmo de vida estanque, ao passo que é no imprevisto e no incidente que pode haver lugar para o sujeito. É na dialética entre a rotina e o imprevisto que o sujeito aparece, dando suas soluções e fazendo suas escolhas de vida" (Marcos, 2004, p.11).

A prática das oficinas, na internação, propõese a ser esse espaço da diversidade, da prática por muitos, da reinvenção do cotidiano (conceito desenvolvido em Marcos, 2004) que, dada a complexidade e a diversidade de manifestações da psicose, se torna um lugar de ampliação e acolhimento de vários discursos: o estético, o clínico e o político.

Nas novas abordagens do tratamento na saúde mental, o espaço da internação é flexibilizado.
Desde que não ofereça riscos para o paciente e para os outros, as famílias são parceiras no tratamento e convidadas a participar, até mesmo adentrar o espaço institucional e suas atividades. Da mesma forma, para o paciente, conforme o caso, a internação não é rígida e pode constituir-se numa ponte entre a vida privada e a social.

Nas oficinas, os pacientes podem apropriar-se do ambiente do hospital e incrementar as trocas relacionais. O pátio, os jardins, o centro cultural, o salão de beleza, a biblioteca, lugares do hospital que os pacientes não usam com freqüência são ocupados. Oferecem-se atividades socioculturais, como cinema, música, teatro, partida de futebol entre instituições, festas comemorativas e outros eventos. Recentemente, realizou-se o desfile "Moda Primavera-Verão do HRS". Para exibir as novas roupas dos pacientes internos do hospital, confeccionadas pela divisão de costura da instituição, foi produzido um desfile dos pacientes.

A ênfase no espaço relacional e na reinvenção do cotidiano do hospital, no poder de decisão sobre suas atividades e no uso do direito de ir e vir fundamenta a nova prática de reabilitação do paciente psiquiátrico na instituição. A possibilidade desses sujeitos de se expressar, de explorar as relações e de circular como cidadãos é retomada, no seu sentido literal e simbólico, como rede subjetiva que sustenta a inserção social.

"As práticas rotineiras são um processo constante de apropriação do tempo e do espaço. Sendo assim, a regulação e o funcionamento do cotidiano transformam-se em um recurso terapêutico a mais na reabilitação psicossocial do paciente, na recuperação do uso do próprio corpo, do espaço e do tempo. O cotidiano pode, então, funcionar como suplência à ordem simbólica e como espaço de construção e presentificação de um Outro menos invasivo (Marcos, 2004, p.6). 
Numa oficina de jornal no HRS, propôs-se, certa vez, uma discussão entre os pacientes após a leitura de notícia sobre o tratamento de saúde na rede pública. Tal iniciativa exemplifica a consciência e a argumentação dos pacientes sobre sua cidadania. Eis parte do que se escutou:

_ "Aqui tem boa comida, mas a vida não se resume só no dormir, tomar remédio e comer. Queremos mais atividades. Isso aqui parece uma prisão".

$\mathrm{Na}$ interlocução, outro paciente comentou:

_ "Fora dessas paredes, eu só sou um 22."

A estagiária de Psicologia então perguntou:

_ "O que é 22"?

Ao que o outro respondeu:

_ "22 é louco. Aí fora eu sou considerado louco".

E o que reivindicou mais atividade na internação disse:

_ "Louco, não. Você é um incompreendido!" As oficinas possibilitam uma apropriação da história de vida desses sujeitos. Ao produzirem um texto, ao lerem ou recitarem um poema, os pacientes muitas vezes se remetem ao seu passado, compartilhando com os colegas sua história de vida, histórias que sustentam vivências de dor e sofrimento, de profunda angústia e desumanização. Por vezes emocionam-se e fazem circular suas lembranças, motivando, no outro também, a expressão de relatos pessoais. Cada encontro é inusitado, e, no imprevisto, pode proporcionar aprendizagem, produção, intercâmbio, ampliação das relações e mergulho no universo cultural, permitindo ao sujeito escapar à imposição do que é massificado em sua rotina, ao mesmo tempo oferecendo resistência ao que é singular e próprio desse sujeito. O trabalho de coordenador das oficinas é o de acolher os sons, as falas, as formas, os atos, afirmando que há ali um sujeito com algo a dizer e a fazer, interessando-se por esse algo e esforçando-se por buscar um sentido nesse fazer.

\section{O papel do coordenador}

Tem-se combatido, nas novas abordagens do tratamento da loucura, o excesso dos discursos psi (psiquiatria e Psicologia) e defendido o trabalho das atividades nas instituições, nas oficinas, por exemplo, por profissionais de outras áreas. É o caso das oficinas nos centros de convivência coordenadas por artistas, por exemplo. Contudo, na internação, faz-se necessário, para um bom desempenho do trabalho, que se compreendam as particularidades da psicose e seu manejo.

A psicanálise é tomada, aqui, como a referência teórica que melhor se aplica ao conhecimento dos laços que o psicótico estabelece com o Outro e sobre a dimensão clínica que abarca a prática exercida por muitos no tratamento da psicose.

Coordenar uma oficina é estar à escuta de uma linguagem muitas vezes sem palavras, a partir da qual essas produções podem instituir canais de troca e encontro e criar novos universos existenciais. As atividades devem ser pensadas, planejadas e orientadas por parâmetros éticos e estéticos e por uma equipe interdisciplinar, conciliadora dos diversos discursos.

Portanto, ser coordenador de oficinas com psicóticos internados exige uma especificidade na mediação com o paciente. Entre a atividade, o que ela pode representar para o paciente no seu cotidiano e o próprio paciente, coloca-se o coordenador, que deve estar ciente de seu papel. Neste, incluem-se o manejo da relação com o psicótico e a consciência dos efeitos da oficina para o paciente. É a teoria que medeia a relação entre o coordenador e o paciente, seu conhecimento sobre a psicose e o lugar que a oficina ocupa na internação. 
"Em outras palavras, ao extrair da própria realidade um produto concreto inédito, o psicótico produziria um esvaziamento desse Outro absoluto que o aterroriza, podendo deixar o lugar de objeto do seu gozo para ocupar o lugar de um autor, produtor de um objeto com consistência simbólica"

Guerra
A dimensão da clínica está presente no cotidiano das oficinas, em um olhar e uma escuta atentos ao sujeito. Sabe-se que o que orienta a condução do tratamento e a reabilitação do paciente portador de transtornos mentais são suas produções sintomáticas e seus arranjos subjetivos, ou seja, o discurso do sujeito e não o discurso ideal político da autonomia.

Pode-se perguntar, então: as oficinas, apesar de não se constituírem no espaço clínico, na internação, podem produzir efeitos clínicos que, necessariamente, não acontecem no espaço do tratamento? Quais seriam esses efeitos? As atividades da oficina funcionam como o que se poderia chamar de uma "extensão" da clínica, onde o efeito terapêutico, além de ser de cunho psicossocial, de acordo com a intervenção do coordenador, pode ser o de se possibilitar o posicionamento do psicótico como sujeito, e não como objeto de gozo do Outro.

As oficinas, na internação, como intervenção, pretendem ser facilitadoras da comunicação entre os pacientes. Por isso, no seu manejo, o coordenador não deve visar meramente à realização da atividade proposta, mas, pautado por uma lógica clínica, deve considerar os modos de sustentação do sujeito na lida com cada um.

A psicanálise é a mediação teórica que entende a necessidade de apaziguamento do gozo que invade o psicótico, através de um cálculo estratégico do oficineiro na internação, sustentando o saber de que, segundo Greco (2004),

"a cada vez, deve-se operar um recuo que evite, ao mesmo tempo, a encarnação do perseguidor e o desabamento da crença" (Greco, 2004, p.89).

Na relação com outros pacientes nas oficinas e com o coordenador, pode-se barrar esse imperativo do gozo do Outro da psicose, à medida que o paciente é escutado como sujeito e que ele mesmo pode apropriar-se desse espaço e da criação, estabelecendo, na relação com o fazer, suas próprias regras e limites.

"Em outras palavras, ao extrair da própria realidade um produto concreto inédito, o psicótico produziria um esvaziamento desse Outro absoluto que o aterroriza, podendo deixar o lugar de objeto do seu gozo para ocupar o lugar de um autor, produtor de um objeto com consistência simbólica" (Guerra, 2004, p.51).

"A oficina funcionará para um participante se, de alguma maneira, produzir através da substancialidade do material disponibilizado ou do objeto criado, um elemento com densidade sobre o qual o psicótico possa localizar o gozo invasivo que assoberba sua economia libidinal, fazendo laço com a linguagem ao significar essa produção a partir da lógica particular com a qual lida com a realidade" (Guerra, 2004, p.55). As oficinas funcionam para os sujeitos que permitem o estabelecimento do enlaçamento de sua singularidade com o universal da linguagem, da cultura; por isso mesmo, não há exigência a ser seguida numa oficina.

A ética possível das oficinas é a de possibilitar a produção de uma subjetividade que enriqueça, de modo contínuo, a relação do psicótico com o mundo.

\section{Relato de experiência}

\section{A oficina de letras e jornal}

As oficinas de letras e jornal são desafiantes no que diz respeito ao manejo do grupo. Os pacientes internos são convidados a participar da oficina, tratando-se, na maioria das vezes, de pessoas diferentes a cada encontro. A particularidade estrutural dos freqüentadores da oficina recomenda, além de prudência, certo saber sobre a psicose, de forma que o coordenador evite uma postura de professor 
ou educador, de pai ou de médico. O inesperado manifesta-se e a imprevisibilidade é marca da psicose.

Para se dirigir uma oficina com psicóticos, temse de estar atento ao tipo muito particular e maciço de transferência que o vínculo com o psicótico propicia. É importante montar manobras e recuos estratégicos para lidar com tal particularidade.

Nas palavras de Greco (2004):

"As oficinas com psicóticos agrupam singularidades tão explícitas que só nos resta escutar uma a uma. São muitas idéias, poemas, recitações circulantes em meio aos delírios e alucinações. São pacientes medicados, outros em quadros agudos, dispersos, querelantes, sem limite. Trata-se de fazer conviver diferenças, singularidades absolutas, inibições absurdas e certezas plenas, em um espaço em que o laço social é mais uma meta que pré- condição de trabalho"(Greco, 2004, p.85).

O oficineiro não é passivo. Pelo contrário, deve implicar-se no processo criativo que desencadeia, estar atento aos imprevistos e tentar sustentar a proposta de uma atividade do começo ao fim.

A oficina de letras e jornal é um espaço de convívio, criação e transformação, para o qual convergem experiências, descobertas e questionamentos no campo da palavra falada e escrita. Não visa, portanto, a atingir uma produção literária nem um produto final.

Em seu livro "Coisa de Louco" (1998), Lúcia Castelo Branco aborda uma oficina de poesias com psicóticos e afirma que loucura e a poesia se tangenciam. A mais nítida fronteira que se estabelece entre o poeta e o psicótico é que o psicótico permanece, de certo modo, assujeitado a esse mundo de palavras, que parece falar através dele, diferentemente do poeta, que pode fazer-se sujeito em meio à linguagem que o cerca.
A psicose é produtora de certos efeitos de linguagem. O psicótico redige um texto fragmentado, com partição de significantes e empilhamento de substantivos, o que caracteriza a metáfora delirante. A transformação da metáfora delirante em um texto, um escrito, é a função clínica desse tipo de trabalho com o psicótico, que torna possível abrir uma via secundária para um sujeito para quem faltou a via principal. A metáfora delirante, que não cessa de funcionar como tamponagem, substituição do que falta, não significa que não possa funcionar como produção de sentido e, muitas vezes, de efeito poético. A criação nas oficinas de letras e jornal pretende, mesmo que não atinja o objetivo "literário", atuar de forma diversa na cadeia discursiva do sujeito psicótico.

Como coordenadores de uma oficina com psicóticos, deparamo-nos, por um lado, com a realidade do intratável da psicose, e, do outro, com as lições que podemos tirar da lógica das "soluções" ou das invenções da psicose. É a posição de sujeito que supõe não saber.

\section{A oficina de salão de beleza}

Essa oficina consiste na apropriação de um "salão de beleza" montado dentro da instituição, na enfermaria feminina, com material de doações. Nela, os estagiários realizam o cuidado da aparência das pacientes: fazem suas unhas, lavam e penteiam seu cabelo, etc. Em geral, as pacientes gostam desse universo feminino e identificam-se com ele, com batons, esmaltes, espelhos, escovas e secadores de cabelo, maquiagem...

A atividade do salão de beleza faz com que o coordenador tenha uma função próxima à de cuidador, já que deve estar aberto ao contato corporal com a paciente. Tem um sentido estético, de higienização, de convívio, de fazer borda na corporalidade do psicótico, tão maltratada na psicose. Tanto pode ser um 
momento de prazer e bem-estar com o corpo quanto suscitar angústia e dificultar o manejo com a paciente. A concretude do corpo, sua deflagração de realidade, sua marca inscrita no simbólico não se constituem na psicose. O sujeito objetifica seu corpo, que, para ele, passa a ser lugar de inscrição do desejo do outro, nesse imperativo de gozo próprio da psicose.

Nessa deficiência, imprecisão de limite entre o próprio corpo e o corpo do outro, através da oficina, a paciente pode experimentar a sensação corporal como um elemento constitutivo de sua imagem corporal, identificadora, que limita, contém, contorna, separa. No lugar de serem cuidadas, as pacientes passam a se cuidar e a cuidar umas das outras, estimuladas pelo ambiente do salão de beleza.

Não devemos, enquanto oficineiros, lidar com a "corporalidade" do psicótico desavisadamente. A atenção e o conhecimento da psicose são indispensáveis. À medida que trabalhamos com psicóticos, vemos que a loucura não é só sofrimento: é uma solução, um modo de existência próprio, que faz suplência ao insuportável. Por isso, a relação afetiva que o psicótico estabelece com o outro é desestabilizada, imprevisível, despolarizada, apaixonada. Assim, ao mesmo tempo em que se mostra dotado de uma afeição quase pueril, pode fazer-se hostil.

Ao passo que nos despimos de nossos preconceitos, que, com a experiência, desmitificamos a psicose, vamos aperfeiçoando a forma de manejo com esses pacientes. 亡̀ justamente aqui que se situa o incompreendido, o intratável da psicose, é no ponto em que o enigma se faz na falta de sentido, que a nossa lógica não alcança. Ficanos claro que é o medo inconsciente da nossa própria "loucura" que nos ameaça.

Aprendemos, com a loucura alheia, a precariedade de nossos pensamentos, a transitoriedade de nossas percepções e identidades, a intensidade como experiência e a vivência de ruína.

Mais que respostas, essa experiência suscita várias perguntas: como legitimarmos a experiência das oficinas para que realmente se constituam em espaço de cidadania para os sujeitos? Qual a postura ética do coordenador das oficinas? 


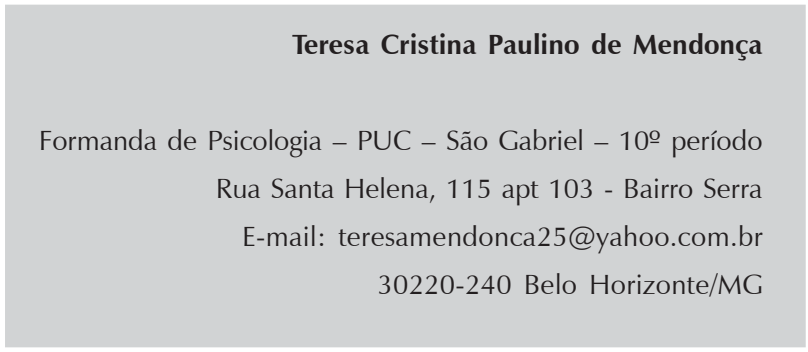

Recebido 11/04/05 Reformulado 03/10/05 Aprovado 28/11/05

BRANCO, L.C. Coisa de Louco. Belo Horizonte: Mazza, 1998.

GOFFMAN, E. Manicômios, Prisões e Conventos. São Paulo: Perspectiva, 1974.

GRECO, M.G. Oficina: uma Questão de Lugar? In Oficinas Terapêuticas em Saúde Mental - Sujeito, Produção e Cidadania. Rio de Janeiro: Contracapa, 2004
GUERRA, A. M. C. Oficinas em Saúde Mental: Percurso de uma História, Fundamentos de uma Prática. In Oficinas Terapêuticas em Saúde Mental - Sujeito, Produção e Cidadania. Rio de Janeiro: Contracapa, 2004.

MARCOS, C. M. A Reinvenção do Cotidiano e a Clínica Possível nos Serviços Residenciais Terapêuticos (não editado) 2004.

Referências 